\title{
Knowledge and psychosocial wellbeing of nurses caring for people living with HIV/AIDS (PLWH)
}

\author{
Lufuno Makhado $^{a, *}$, Mashudu Davhana-Maselesele ${ }^{b, 1}$ \\ ${ }^{a}$ Department of Nursing Sciences, Faculty of Agriculture, Science and Technology, North West University, Mafikeng \\ Campus, South Africa \\ ${ }^{\mathrm{b}}$ NWU (Mafikeng Campus), Private Bag x 2046, Mmabatho, 2735, South Africa
}

\section{A R T I C L E I N F O}

Article history:

Received 30 April 2015

Accepted 9 October 2015

Available online 18 February 2016

Keywords:

Nurses

HIV and AIDS

Knowledge

Psychosocial wellbeing

Burnout

Impact of AIDS

\begin{abstract}
A B S T R A C T
The challenges of caring for people living with HIV (PLWH) in a low-resource setting has had a negative impact on the nursing profession, resulting in a shortage of skilled nurses. In response to this shortage and perceived negative impact, we conducted a descriptive, cross-sectional study to describe the level of knowledge and psychosocial wellbeing of nurses caring for PLWH at a regional hospital in Limpopo Province, South Africa. A total of 233 nurses, the majority being female, participated and were stratified into professional nurses $(n=108)$, enrolled nurses $(n=58)$ and enrolled nursing auxiliaries $(n=66)$. Data were collected using HIV/AIDS knowledge questionnaire, Maslach Burnout Inventory; AIDS Impact Scale and Beck's Depression Inventory. The total knowledge score obtained by all the participants ranged from 2 to 16 , with an average of 12.93 (SD = 1.92) on HIV/AIDS knowledge. Depersonalization (D) (83.7\%) and emotional exhaustion (EE) (53.2\%) were reported among participating nurses caring for PLWH. Burnout was higher among professional nurses as compared to both enrolled nurses and enrolled nursing auxiliaries. There was a moderate negative significant correlation between HIV knowledge with the nurses' emotional exhaustion $(r=-0.592)$, depression $(r=-0.584)$ and stigma and discrimination $(r=-0.637)$. A moderate to high level of burnout was evident among all levels of nurses. These findings lead to the recommendations for support of nurses caring for PLWH that include structured nursing educational support, organisational support with respect to employee wellness programmes that address depression and work burnout, as well as social support. The provision of these support mechanisms has the potential of creating a positive practice environment for nurses in the Vhembe District of the Limpopo Province in particular, and South Africa in general, and in improved care for PLWH.
\end{abstract}

(c) 2015 The Authors. Publishing services by Elsevier B.V. on behalf of Johannesburg University. This is an open access article under the CC BY-NC-ND license (http:// creativecommons.org/licenses/by-nc-nd/4.0/).

\footnotetext{
* Corresponding author. Tel.: +27 018389 2236, +27 0603551934 (mobile); fax: +27 0183892052.

E-mail addresses: lufuno.makhado@nwu.ac.za (L. Makhado), mashudu.maselesele@nwu.ac.za (M. Davhana-Maselesele).

${ }^{1}$ Tel.: +27 018389 2005/2007, +27 0833101160 (mobile); fax: +27 0183892420.
}

Peer review under responsibility of Johannesburg University. 


\section{Introduction and problem statement}

HIV has strongly impacted the health status of various nations globally since its surfacing; with sub-Saharan countries being the most affected (UNAIDS, 2008). South Africa is reported to have the largest population of people living with the disease in the world, with 5.26 million people estimated to be infected in 2013 (Statistics South Africa (StatsSA), 2013), followed by Nigeria in 2nd place and India being the 3rd largest population with HIV infected with more than 2 million people reported due to its large overall population, but with a prevalence rate of 0.30 in comparison to the prevalence rate of 0.60 in the US and 18.10 in South Africa (Central Intelligence Agency, 2011). Furthermore, the number of people living with HIV (PLWH) in South Africa is on a steep increase, with approximately 100,000 additional PLWH each year (UNAIDS, 2012).

HIV remains a challenge in South Africa. The total number of persons living with human immunodeficiency virus (HIV) (PLWH) in South Africa increased from an estimated 4,21 million in 2001 to 5,38 million by 2011 (StatsSA, 2011), and in 2013 an estimated $10,0 \%$ of the total population is HIV positive (StatsSA, 2013). An HIV knowledge deficit amongst nurses has a major impact on their daily work. This is serious, given its potential influence on their safety and the quality of care provided to PLWH. Nurses still lack the necessary knowledge (Delobelle et al., 2009) needed to adequately care for PLWH. In the same context, clinical services for PLWH are rapidly changing, driven by patients' increasing needs due to HIV's evolution into a chronic disease, requiring new skills on the part of the nurses and reshaping them as they were initially equipped only for acute care (Deeks, Lewin \& Havlir, 2013). Nurses are now expected to continually adapt and keep up with new programmes, information and practices. This expectation puts more pressure on them as individuals and overburdens them in their work performance. The current high rate of HIV infection in Limpopo Province, South Africa, coupled with a vacancy rate of $45 \%$ among professional nurses (22\% among enrolled nurses and 49\% among enrolled nursing auxiliaries), calls for a study in assessing the psychosocial wellbeing of nurses as care givers of PLWH.

The rise of PLWH impacts on the already burdened healthcare workforce (UNAIDS, 2008; HIV and AIDS in South Africa (HASA), 2011; Hall, 2005) and predisposes nurses to workplace stress as they carry out their duties of caring for PLWH. This rise calls for policy and guidelines developers to engage in developing guidelines and policies to curb and mitigate HIV by coming up with innovative strategies, programmes, information and practices. Nurses have to implement these guidelines and policies (Bradley-Springer, Stevens, \& Webb, 2010; Brown, 2004) as the frontline health care providers (Hall, 2005) and as a result they end up frustrated (MavhanduMudzusi, Netshandama, \& Davhana-Maselesele, 2007) and experiencing stress, stigma and emotional exhaustion (Davhana-Maselesele \& Igumbor, 2008). This increases the burden of caring on the already short staffed health care facilities.

There is a critical shortage of nurses in South Africa and given the rise in HIV infection, the increase in need for care rises sharply. Furthermore, inadequate knowledge and skills related to HIV and AIDS care among nurses poses major barriers to achieving the health-related Millennium Developmental Goals (MDGs) (WHO, UNICEF \& UNAIDS, 2010). According to Brown (2004), nurses are expected to care for, nurture, comfort and advocate for patients regardless of the challenges they face in the workplace and in their own lives. Nurses have been found to lack the necessary knowledge and skills to carry out their responsibilities to offer HIV and AIDS care, and this has resulted in HIV and AIDS care work frustration (Mavhandu-Mudzusi et al., 2007). On the converse, knowledge about HIV and AIDS and the needs of PLWH can help alleviate fear, anxiety and stigma associated with caring for the PLWH (Walusimbi \& Okonsky, 2004). The evolution of HIV infection into a chronic disease has implications across all clinical care settings. Every nurse should be knowledgeable about the prevention, testing, treatment and chronicity of the disease in order to provide high-quality care to people with or at risk of HIV. It is important therefore to have an understanding of the changing epidemiology of the disease, the most recent HIV intervention developments and the nursing implications of the on-going epidemic (Bradley-Springer et al., 2010).

There is insufficient published literature on the impact of AIDS with regard to health workforce. Although HIV and AIDS have a major impact on the health sector, the disease cannot entirely be blamed for the challenges that health care workers have to face in the South African health facilities (UNAIDS, 2008). A number of other factors also influence the workplace. To begin with, political and economic changes in the mid-nineties had a major impact on the demand for health services in South Africa (HASA, 2010). As a result of a unified and transformed health system, large sections of the population, who never had access to health care before, are now entitled to free health services (Hall, 2005). Also, betterequipped facilities are crowded due to people "shopping around" for efficient health services (HASA, 2010). In addition, many South Africans have been forced into subsidized health care over the past decade due to increases in the cost of medicine and medical services, as well as rising unemployment (HASA, 2010).

Furthermore, little research-based evidence exists on burnout of nurses related to the workplace, family and community stresses (Shisana et al., 2004). Nurses caring for PLWH may be at a higher risk of emotional exhaustion, stress, stigma and work-related injuries, including HIV infection (DavhanaMaselesele \& Igumbor, 2008). In other studies on burnout among health care workers, Van Servellen and Leake (in Hall, 2005) reported a strong association between job tension and emotional exhaustion among hospital nurses, irrespective of the unit in which they work while Bellani et al., (1996) and Gueiritault-Chalvin, Kalichman, Demi, and Peterson (2000) found that perceived workload would significantly predict burnout among AIDS caregivers. Bellani et al., (1996) also link health care workers' fear of contagion with high burnout, meaning the perceived workload of nurses and fear of contagion leads to distorted psychosocial wellbeing of nurses. The challenges of caring for PLWH in a low-resource setting, in many health care centres in SA, have had a negative impact on the nursing profession, resulting in a shortage of skilled nurses (Ramathuba \& Davhana-Maselesele, 2013; Hall, nd; 
Hable, Dussault \& Dovlo, nd). Therefore, the aim of this study was to describe the state of nurses' knowledge of HIV and their psychosocial wellbeing as care givers of PLWH at a regional hospital in Limpopo Province in order to make recommendations for support to nurses caring for PLWH.

\section{Research objectives}

The study objectives were to describe the level of knowledge and establish the level of burnout and depression among different groups of nurses caring for PLWH; to assess and describe the impact of AIDS among nurses; and to establish a relationship between HIV knowledge and the psychosocial wellbeing of nurses caring for PLWH.

\section{Definition of key concepts}

Burnout refers to long-term exhaustion and diminished interest in work, herein referred to as a combination of 'maladaptive' psychological and behavioural responses coming out from loss of interest in work and PLWH, dissatisfaction, heavy stressful work activities (Visintini et al., 1996) which incorporate depersonalisation, emotional exhaustion and personal accomplishment.

Psychosocial well-being in this study was determined by the level of burnout, depression and the impact of AIDS on nurses' care-giving role. Individuals' psychosocial wellbeing is defined with respect to three core domains, namely: human capacity, social ecology and culture and values (The Psychosocial Working Group, 2003). In this study, focus is on human capacity, which is fundamentally constituted by the physical and mental health, knowledge and skills of an individual.

\section{Significance of the study}

It is hoped that the findings of this study will help policy makers and programme planners in developing policies and programmes that will support nurses' knowledge and skills development, address burnout, and promote positive working environment, thus ultimately improving the quality of care for PLWH.

\section{Research methods and design}

\subsection{Context of the study}

The study is set in Limpopo Province which has 34 district hospitals, and primary health care facilities ( 22 health centres, 396 fixed clinics and 3977 mobile clinics). The workforce consists of 2109 professional nurses working at primary health care facilities and 2929 working at district hospitals (DoH Limpopo, 2008). Limpopo, one of the nine provinces of South Africa, has the highest nurse vacancy rate in the country at $68 \%$ (SAIRR, 2013). Limpopo province is the fifth most populated province and it comprises five (5) districts, namely: Vhembe, Capricorn, Mopani, Sekhukhune and Waterberg District. Limpopo province remains the third lowest province affected by the HIV epidemic, with a prevalence of 22.1\% (South African National AIDS Council (SANAC), 2013). The study focused on the Vhembe District and one regional hospital was selected purposively.

The Vhembe District was selected for inclusion in the study as part of a major study (Caring for carers: Responding to nurses' needs), which consists of four sub-districts, including the Thulamela District in which the regional hospital is situated. Limpopo is mostly rural and is the poorest province in South Africa (StatsSA, 2009). Thulamela District was chosen as it has very limited resources with most of the place being very rural. The study population comprised of nurses working with HIV and AIDS patients within the hospital and at the OutPatient Department. The wards where the nurses worked were: Surgical and Obstetric wards, Medical and Palliative wards, HIV clinic and Casualty/Out-Patient Department.

The population of the study was all nurses employed at the regional hospital. Quota sampling was used in the study. The population consisted of 568 nurses that are professional nurses (PN) (256), enrolled nurses (EN) (142), and enrolled nursing auxiliaries (ENA) (161). Stratification for sampling was employed to cater for 3 nursing strata using the sample size for proportion formula (Schaeffer, Mendenhall, \& Ott, 2006) to ensure equal representation of the population. A sample size of 233 was derived and stratified by qualification; that is, PN (109), EN (58), and ENA (66). Efforts were made to recruit equal representation of the nursing categories.

\subsection{Design}

This was descriptive, cross sectional study design to investigate nurses' knowledge and psychosocial wellbeing with regard to their care giving role to PLWH.

\subsection{Data collection and instrument}

A self-administrated questionnaire, hand-delivered to the participants, was used to collect data. Prior to data collection the voluntary nature of the study was made clear and written consent of all participants was obtained following an explanation of the study purpose. Most participants completed the questionnaire immediately after the information session and the remaining ones were collected the following day. Collected data were stored in a locked cabinet, without any names of participants on these documents. Participants were informed of the right to withdraw from the study at any time and that deciding not to participate in the study would not affect their employment status.

The instrument incorporated participants' demographic and professional profile; HIV/AIDS knowledge questions (Forrest \& Kanabus, 2003); the Maslach Burnout Inventory (MBI) (Maslach \& Jackson, 1981); the AIDS Impact Scale (AIS) (Bennett, Miller, \& Ross, 1995); and the Beck's Depression Inventory (BDI) (Beck, 1967). These are all standardised inventories and scales.

Demographic and professional variables included gender, age, qualification, duration of employment per allocation in the ward and in the hospital, and lastly, unit of operation. An 
HIV knowledge questionnaire was derived from Forrest and Kanabus (2003), composed of HIV and AIDS prevention and precaution; agent and immunology; transmission and incidence; course and manifestations; and general knowledge questions. The AIS contains 28-items measuring the impact of HIV/AIDS while caring for PLWH. The scale is grouped into five scales: 'stigma and discrimination' (AIS-S\&D), 'identification with others' (AIS-ID), 'social reward' (AIS-SR), 'grief and loss' (AIS-G\&L) and 'peer relationship/loss tolerance' (AIS-PR/LT) (Bennett \& Kelaher, 1993). Each of these scales was designed to measure a different way of coping with stress related to working with HIV-infected patients.

The MBI (Maslach \& Jackson, 1981) is a 22-item tool designed to measure burnout under three dimensions: personal accomplishment, emotional exhaustion and depersonalization. The MBI was used to measure the strength to continue working with PLWH and exhaustion in service delivery in relation to level of stress in the workplace (Maslach, Jackson, \& Leiter, 1996). This takes 10-15 min to complete. The BDI (Beck, 1967) is a series of questions developed to measure intensity, severity and depth of depression. Its long version is composed of 21 questions, each designed to assess symptoms common among people with depression (Polgar, 2003). Participants' aggregate score on the BDI were rated from normal to extreme depression. Items 1 to 13 assess symptoms that are psychological in nature, while items 14 to 21 assess more physical symptoms (Polgar, 2003). All parts of MBI and BDI were measured. With AIS, items 2,8,10 and 11 were not included.

\subsection{Data analysis}

Statistical Packages for Social Sciences (SPSS) (PASW statistics 18) computer software was used for data analysis. Knowledge levels were cross tabulated against qualification to detect possible patterns and variations. The descriptive statistics of measures of AIS, BDI and MBI scales were compared across the 3 nursing categories. Bivariate Correlation Analysis was done to establish possible association among measures of AIS, MBI, BDI and total knowledge score (TKS). Regression analysis was done to establish the predictors of measures of burnout among nurses using the Backward and Enter methods.

\subsection{Ethical considerations}

Ethical clearance was granted by the North-West University Ethics Committee (Ethics Number: NWU-00030-11-A9) and permission was granted by the Limpopo Provincial Department of Health. The study protected the rights and dignity of the participants, and they were informed that the research was of no harm to them. Participants were recruited from the nurses' respective wards at the hospital. Voluntary participation was encouraged and participants were informed of their right to terminate their participation at any given point if they felt uncomfortable. An information sheet was provided to inform them about the purpose of the study. Written consent of all participants was sought after detailed information about the research was given to participants. The researchers ensured that all collected data were stored in a locked place and electronic data were saved in a password-protected device to which only the researchers had access. No names of the participants and hospital were divulged.

\section{Results}

A total of 233 out of 235 (99.1\%) surveys distributed were returned. $77.7 \%$ participants were females and most responses came from the Medical and Palliative wards (36.9\%), surgical wards (26.2\%) and Maternity wards (14.6\%). The sample was made up of PN (47\%), ENA (28\%) and EN (25\%) as shown in Table 1.

The highest possible knowledge score was 16 . The TKS obtained by all the participants ranged from 2 to 16 with an average of $12.93(\mathrm{SD}=1.92)$. Only $\mathrm{PN}$ and EN obtained a mean knowledge score above the group average, thus making $81 \%$ of all nurses score higher than the mean knowledge score. Nurses varied when it came to receiving any training or workshop in relation to HIV and AIDS. Slightly more than half (52\%) of enrolled nurses reported training compared to professional (34.9\%) and enrolled nursing auxiliaries (39.4\%). Table 2, Table 3, Table 4, Table 5.

The majority of ENAs scored high in peer relations/loss tolerance $(97 \%)$, grief and loss $(96 \%)$ and social reward followed by other groups. Most PN (70.6\%) scored high in identification with others followed by ENA (69\%) and EN (51.7\%). There was a significant difference between the nursing groups with regard to peer relations/loss tolerance $(p=0.045)$ and grief and loss $(p=0.000)$, but there was no significant

\begin{tabular}{|c|c|c|c|}
\hline $\begin{array}{l}\text { Demographic } \\
\text { characteristic }\end{array}$ & $\begin{array}{c}\text { PN } \\
(n=109)\end{array}$ & $\begin{array}{c}\text { EN } \\
(n=58)\end{array}$ & $\begin{array}{c}\text { ENA } \\
(\mathrm{n}=66)\end{array}$ \\
\hline \multicolumn{4}{|l|}{ Age } \\
\hline $21-30$ & $40(36.7 \%)^{a}$ & 0 & $22(33.3 \%)$ \\
\hline $31-40$ & $21(19.3 \%)$ & $27(46.6 \%)^{a}$ & $19(28.8 \%)$ \\
\hline $41-50$ & $30(27.5 \%)$ & $21(36.2 \%)$ & $24(36.4 \%)^{a}$ \\
\hline 50 and above & $18(16.5 \%)$ & $10(17.2 \%)$ & $1(1.5 \%)$ \\
\hline \multicolumn{4}{|l|}{ Gender } \\
\hline Male & $14(12.8 \%)$ & $11(19.0 \%)$ & $27(40.9 \%)$ \\
\hline Female & $95(87.2 \%)^{a}$ & $47(81.0 \%)^{a}$ & $39(59.1 \%)^{a}$ \\
\hline \multicolumn{4}{|l|}{$\begin{array}{l}\text { Enrolled in any } \\
\text { course presently }\end{array}$} \\
\hline Not enrolled & $99(90.8 \%)^{a}$ & $32(55.2 \%)^{a}$ & $64(97.0 \%)^{a}$ \\
\hline Enrolled & $10(9.2 \%)$ & $26(44.8 \%)$ & $2(3.0 \%)$ \\
\hline \multicolumn{4}{|l|}{ Ward allocation } \\
\hline OPD/Casualty & $9(8.3 \%)$ & $6(10.3 \%)$ & $3(4.5 \%)$ \\
\hline $\begin{array}{l}\text { Medical and } \\
\text { palliative wards }\end{array}$ & $41(37.6 \%)^{a}$ & $22(37.9 \%)^{a}$ & $23(34.8 \%)$ \\
\hline Surgical wards & $20(18.3 \%)$ & $16(27.6 \%)$ & $25(37.9 \%)^{a}$ \\
\hline ICU/OT/Private ward & $13(11.9 \%)$ & $7(12.1 \%)$ & $14(21.2 \%)$ \\
\hline Maternity wards & $26(23.9 \%)$ & $7(12.1)$ & $1(1.5 \%)$ \\
\hline \multicolumn{4}{|l|}{$\begin{array}{l}\text { Years of service at } \\
\text { hospital }\end{array}$} \\
\hline Less than 2 years & $7(6.4 \%)$ & $08(13.8 \%)$ & $9(13.6)$ \\
\hline $2-4$ years & $44(40.3 \%)^{a}$ & $25(42.2 \%)^{a}$ & $23(34.8 \%)$ \\
\hline $5-10$ years & $14(12.8 \%)$ & $6(10.3 \%)$ & $33(50.1 \%)^{a}$ \\
\hline $11-20$ years & $18(16.2 \%)$ & 19(33.7\%) & $1(1.5 \%)$ \\
\hline Above 20 years & $26(24.3 \%)$ & 0 & 0 \\
\hline
\end{tabular}

${ }^{a}$ Highest frequencies and percentages. 
Table 2 - Descriptive and frequency statistics HIV

\section{knowledge.}

\begin{tabular}{crrrc} 
& Min & Max & Mean & SD \\
\hline TKS & 2.00 & 16.00 & 12.9399 & 1.92439 \\
PN & 2.00 & 16.00 & 13.0550 & 2.21458 \\
EN & 10.00 & 16.00 & 13.1379 & 1.61624 \\
ENA & 10.00 & 15.00 & 12.5758 & 1.60825 \\
\hline
\end{tabular}

Level of knowledge among nurses caring for PLWHA

\begin{tabular}{lccc}
\hline & Below average & Above average & $\mathrm{x}^{2}(\mathrm{p}$-value) \\
\hline PN & 56.9 & 43.1 & $1.580(0.454)$ \\
EN & 55.2 & 44.8 & \\
ENA & 65.2 & 34.8 & \\
\hline
\end{tabular}

Key: TKS - total knowledge score.

difference in ID, SR and S\&D. The vast majority of all nursing groups reported moderate to high depersonalization and there was no significant difference between the groups $(p=0.249)$. Emotional exhaustion was common among all levels of nurses and only one quarter (25\%) of nurses scored in the moderate to high range in personal accomplishment. 57\% of the nurses reported borderline to extreme depression, with EN having the highest percentage (67.3\%).

A negative moderately significant association was evident among ENAs between total knowledge score with emotional exhaustion $(r=-0.592)$, depression $(r=-0.584)$ and stigma and discrimination $(r=-0.637)$. There was a strong association among the overall nursing group between the emotional exhaustion and depression $(r=0.796)$. However, there was a weak relationship between emotional exhaustion and personal accomplishment $(r=0.278)$. ENA had the strongest association between depression and emotional exhaustion $(r=0.936)$, between social reward and personal accomplishment $(r=0.595)$ and depression $(r=0.737)$. There was a moderate significant association among overall nursing group between DEP and S\&D $(r=0.546)$.
Nurses' experience of stigma and discrimination significantly predicted emotional exhaustion scores, $\beta=0.63$, $\mathrm{t}=11.18, \mathrm{p}<0.001$ and also explained a significant proportion of variance with adjusted $r^{2}=0.38, F=29.05, p<0.001$.

\section{Discussion}

1. The results of the study showed that the mean of HIV knowledge score across all nursing categories was $81 \%$ of correct answers, which is in fact higher than the means of $55 \%$ and $75 \%$ of other studies (Askarian, Hashemi, Jaafari, \& Assadian, 2006; Oyeyemi, Oyeyemi, \& Bello, 2006; Suominen et al., 2010) which indicates advances in HIV knowledge. There was no significant variation in terms of the mean knowledge scores between the categories regardless of qualification. $59 \%$ of all nurses had not received specific training in HIV/AIDS. Previous studies indicate that the HIV/ AIDS knowledge level can be enhanced with planned educational programmes on HIV/AIDS (Lohrman et al., 2000; Walusimbi \& Okonsky, 2004). However, it is impressive how high the nurses in this study scored, given their limited opportunities to advance their HIV/AIDS knowledge. This could mean that nurses have other sources of training and learning about HIV/AIDS to improve care for their patients. Given the high number of HIV/AIDS patients seen in the regional hospital and the demonstrated HIV/AIDS training gap among nurses in this hospital, designing a structured curriculum to increase the HIV/AIDS knowledge among nurses is of paramount importance. Ramathuba and Davhana-Maselesele (2011) recommended the need for education on HIV and AIDS to support nurses in their caregiving role, wherein lack of knowledge was said to be the main barrier towards the provision of quality care. This was also supported by a study done by Effa-Heap (1997) indicating that $70 \%$ of nurses felt that they should receive specialized training in order to safely carry out the nursing

Table 3 - Frequencies of measures of burnout, AIDS impact scale and depression.

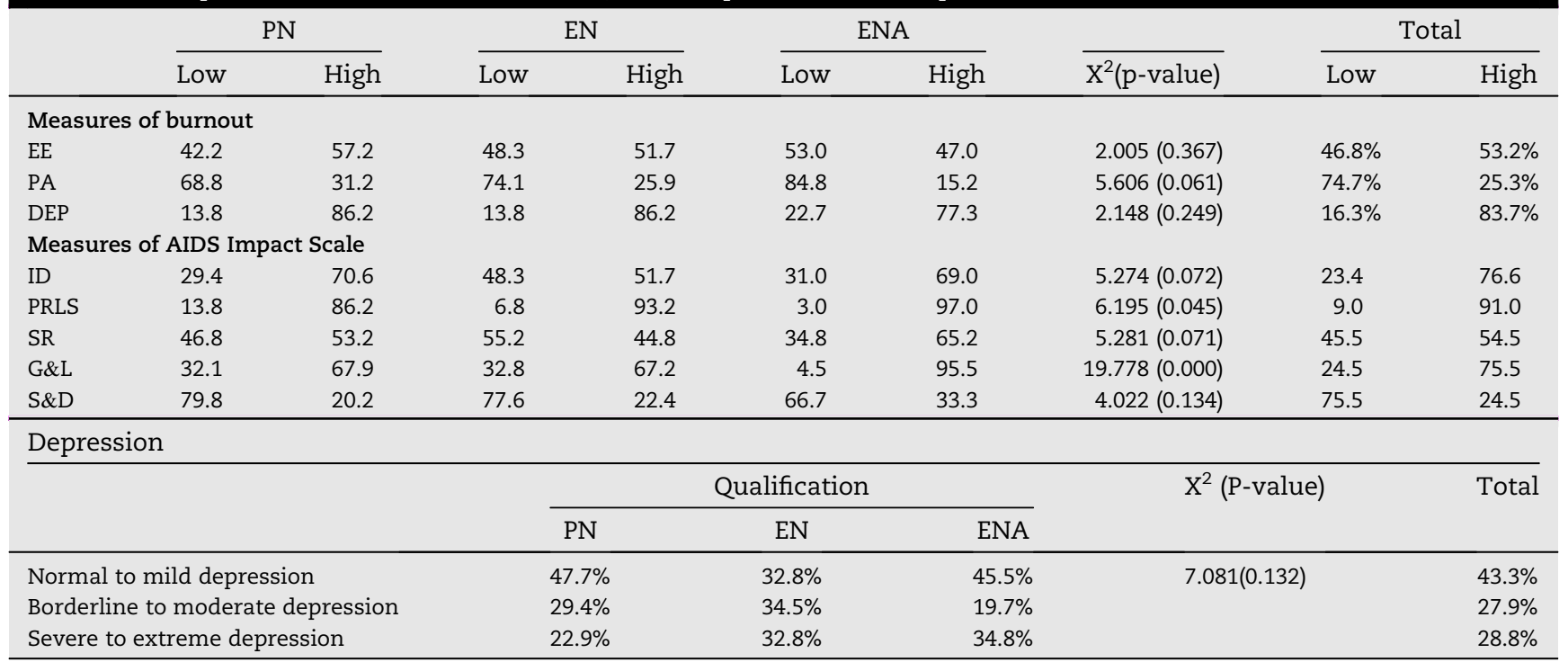


Table 4 - Correlation coefficients of measures of AIS, MBI, BDI and TKS.

\begin{tabular}{|c|c|c|c|c|c|c|c|c|c|c|}
\hline Qualification & $\frac{\text { TKs }}{\text { TKs }}$ & $\frac{\mathrm{D}}{-.048}$ & $\frac{E E}{-.157^{b}}$ & $\frac{\mathrm{PA}}{.035}$ & $\frac{\mathrm{DEP}}{-.191^{\mathrm{a}}}$ & $\frac{\text { PRLS }}{-.080}$ & $\frac{\mathrm{ID}}{.013}$ & $\frac{\mathrm{SR}}{-.086}$ & $\frac{G \& L}{-.102}$ & $\frac{S \& D}{-.257^{a}}$ \\
\hline D 1 & -.099 & & & & & & & & & \\
\hline D2 & -.237 & & & & & & & & & \\
\hline D3 & .189 & D & $.195^{\mathrm{a}}$ & .101 & .111 & -.079 & .015 & .070 & -.026 & -.038 \\
\hline EE1 & .033 & $.344^{a}$ & & & & & & & & \\
\hline EE2 & -.187 & $.528^{\mathrm{a}}$ & & & & & & & & \\
\hline EE3 & $-.592^{\mathrm{a}}$ & $-.283^{b}$ & $\mathrm{EE}$ & $.278^{\mathrm{a}}$ & $.796^{\mathrm{a}}$ & .014 & $.198^{\mathrm{a}}$ & .032 & .056 & $.510^{\mathrm{a}}$ \\
\hline PA1 & .137 & .154 & .169 & & & & & & & \\
\hline PA2 & -.020 & $.355^{\mathrm{a}}$ & $.356^{\mathrm{a}}$ & & & & & & & \\
\hline PA3 & -.180 & $-.253^{\mathrm{b}}$ & $.417^{\mathrm{a}}$ & PA & $.150^{\mathrm{b}}$ & $.208^{a}$ & $.178^{a}$ & $.161^{\mathrm{b}}$ & -.019 & .056 \\
\hline DEP1 & .038 & $.265^{\mathrm{a}}$ & $.733^{\mathrm{a}}$ & .033 & & & & & & \\
\hline DEP2 & -.229 & $.421^{\mathrm{a}}$ & $.716^{\mathrm{a}}$ & .081 & & & & & & \\
\hline DEP3 & $-.584^{\mathrm{a}}$ & $-.261^{\mathrm{b}}$ & $.936^{\mathrm{a}}$ & $.388^{\mathrm{a}}$ & DEP & $.138^{\mathrm{b}}$ & $.241^{a}$ & .098 & .079 & $.546^{\mathrm{a}}$ \\
\hline PRLS1 & -.098 & -.021 & $-.279^{\mathrm{a}}$ & .026 & -.044 & & & & & \\
\hline PRLS2 & .133 & .162 & .239 & $.275^{b}$ & .102 & & & & & \\
\hline PRLS3 & -.173 & $-.436^{\mathrm{a}}$ & $.460^{\mathrm{a}}$ & $.611^{\mathrm{a}}$ & $.472^{\mathrm{a}}$ & PRLS & $.594^{\mathrm{a}}$ & $.489^{\mathrm{a}}$ & $.573^{\mathrm{a}}$ & $.339^{\mathrm{a}}$ \\
\hline ID1 & .065 & .031 & -.028 & .074 & .077 & $.506^{\mathrm{a}}$ & & & & \\
\hline ID2 & .105 & $.425^{\mathrm{a}}$ & $.479^{\mathrm{a}}$ & $.344^{\mathrm{a}}$ & $.311^{\mathrm{b}}$ & $.697^{\mathrm{a}}$ & & & & \\
\hline ID3 & -.216 & $-.550^{\mathrm{a}}$ & $.491^{a}$ & $.272^{\mathrm{b}}$ & $.535^{\mathrm{a}}$ & $.720^{\mathrm{a}}$ & ID & $.550^{\mathrm{a}}$ & $.561^{\mathrm{a}}$ & $.408^{\mathrm{a}}$ \\
\hline SR1 & .008 & -.038 & -.182 & .022 & -.040 & $.561^{a}$ & $.555^{\mathrm{a}}$ & & & \\
\hline SR2 & $-.321^{\mathrm{b}}$ & $.537^{\mathrm{a}}$ & $.492^{\mathrm{a}}$ & -.017 & $.285^{\mathrm{b}}$ & $.296^{\mathrm{b}}$ & $.495^{\mathrm{a}}$ & & & \\
\hline SR3 & -.059 & -.128 & .039 & $.595^{\mathrm{a}}$ & .148 & $.525^{\mathrm{a}}$ & .210 & SR & $.425^{\mathrm{a}}$ & $.337^{\mathrm{a}}$ \\
\hline G\&L1 & -.085 & -.092 & -.020 & -.160 & .105 & $.598^{a}$ & $.616^{a}$ & $.457^{\mathrm{a}}$ & & \\
\hline G\&L2 & .120 & .200 & .212 & .043 & .024 & $.643^{a}$ & $.681^{\mathrm{a}}$ & $.398^{\mathrm{a}}$ & & \\
\hline G\&L3 & -.239 & -.134 & .207 & $.298^{\mathrm{b}}$ & .092 & $.435^{\mathrm{a}}$ & $.249^{b}$ & $.473^{a}$ & G\&L & $.367^{a}$ \\
\hline S\&D1 & -.120 & $.202^{b}$ & $.458^{\mathrm{a}}$ & .000 & $.557^{\mathrm{a}}$ & .155 & $.335^{\mathrm{a}}$ & $.323^{a}$ & $.246^{\mathrm{b}}$ & \\
\hline S\&D2 & -.022 & .111 & $.364^{\mathrm{a}}$ & -.057 & .191 & $.401^{a}$ & $.445^{\mathrm{a}}$ & $.418^{\mathrm{a}}$ & $.404^{\mathrm{a}}$ & \\
\hline S\&D3 & $-.637^{\mathrm{a}}$ & $-.391^{\mathrm{a}}$ & $.732^{\mathrm{a}}$ & $.244^{b}$ & $.737^{a}$ & $.561^{\mathrm{a}}$ & $.546^{a}$ & $.285^{\mathrm{b}}$ & $.440^{\mathrm{a}}$ & \\
\hline
\end{tabular}

Key: 1 - PN, 2 - EN, 3 - ENA,TKS - Total knowledge score, D - depersonalization, EE - Emotional exhaustion, PA - Personal accomplishment, ID - identification with others, PRLT - peer relationship or loss tolerance, SR - Social reward, G\&L - Grief and loss, S\&D - stigma and discrimination.

a Correlation is significant at the 0.01 level (2-tailed).

b Correlation is significant at the 0.05 level (2-tailed).

care of HIV/AIDS patients regardless of where they work. It was further emphasized that nursing people living with HIV/ AIDS requires special skills. However, this study found high knowledge among nurses regardless of their lack of training reported.
There was a significant level of burnout among the nurses caring for $\mathrm{PLWH}$, as $53 \%$ of them reported high emotional exhaustion, and $84 \%$ reported high depersonalisation. The majority (69\%) of nurses had moderate to high levels of burnout, which is consistent with findings of Hayter (1998),

Table 5 - Regression of professional and demographic characteristics, depression and measures of AIDS impact scale on measures of burnout.

\begin{tabular}{|c|c|c|c|c|c|c|c|}
\hline Model & $\mathrm{R}$ & $\mathrm{R}^{2}$ & Adju & & Std. error of the estimate & F & Sig. \\
\hline 5 & .626 & .392 & & & 10.43096 & 29.049 & .000 \\
\hline 6 & .589 & .347 & & & 5.46987 & 29.970 & .000 \\
\hline 7 & .369 & .136 & & & 9.22336 & 8.899 & .000 \\
\hline \multicolumn{8}{|c|}{ Coefficients } \\
\hline \multirow[t]{2}{*}{ Model } & & & \multicolumn{2}{|c|}{$\begin{array}{l}\text { Unstandardized } \\
\text { coefficients }\end{array}$} & Standardized coefficients & $\mathrm{t}$ & Sig. \\
\hline & & & B & SE & Beta & & \\
\hline 5 & \multicolumn{2}{|c|}{$\begin{array}{l}\text { Stigma and discrimination on } \\
\text { emotional exhaustion }\end{array}$} & 3.567 & .319 & .633 & 11.184 & .000 \\
\hline 6 & \multicolumn{2}{|c|}{$\begin{array}{l}\text { Stigma and discrimination on } \\
\text { depersonalization }\end{array}$} & 1.773 & .168 & .620 & 10.567 & .000 \\
\hline 7 & \multicolumn{2}{|c|}{$\begin{array}{l}\text { Peer relationship on personal } \\
\text { accomplishment }\end{array}$} & 1.397 & .291 & .357 & 4.794 & .000 \\
\hline
\end{tabular}

Model 5 (a). Dependent Variable: Emotional exhaustion.

Model 6 (a). Dependent Variable: Depersonalization.

Model 7 (a). Dependent Variable: Personal accomplishment. 
stating that $66 \%$ of informants scored as either moderate or high burnout cases. Chandra, Jairam, and Jacob (2004) also noted high levels of burnout among Indian nurses caring for HIV/AIDS patients. Nurses had lower scores on personal accomplishment, which is said to correspond to higher degrees of perceived burnout (Ghetti, Chang, \& Gosman, 2009). These findings reveal that the higher the depersonalisation and emotional exhaustion perceived by nurses, the lower the positive feelings of personal accomplishment among the nurses.

Professional and enrolled nurses had higher burnout as compared to enrolled nursing auxiliaries. This finding from the current study was in contrast to the findings of a study done by Jodas and Haddad (2009), stating that people with greater education are more prone to burnout. This interplay between burnout and educational levels could be influenced by the context of care where those with lower educational status are providing more direct care to PLWH. However, in lower resource settings, all nursing levels provide direct care to PLWH. Most nurses reported peer relationship which, according to Bennett (1991), can be a protective factor from burnout. In this case, peer relationships and measures of burnout were all high, suggesting the opposite. That is, the more the nurses resort to peer relations/loss tolerance, the higher the burnout they experience.

The majority of nurses reported symptoms consistent with depression. Working with PLWH has been said to lead to depression among nurses (Uys, 2003), and this was evident with majority of nurses reporting borderline to extreme depression in this study. According to Iacovides, Fountoulakis, Kaprinis, and Kaprinis (2003), empirical research suggests that burnout and depression are separate entities, even though they may share several common characteristics. However, this study revealed a significant correlation between emotional exhaustion and depression, which shows that the more emotional exhausted nurses are the more symptoms of depression.

HIV knowledge had a moderately negative relationship with depression, emotional exhaustion, and stigma and discrimination among ENA, suggesting that the more knowledgeable a nurse is the less depressed and emotionally exhausted. This was in line with studies by Theorell et al., (2012); Andersen, Thielen, Nygaard, and Diderichsen (2009) who state that low education was related to high scores of depression. Stigma and discrimination were found to be the main predictors of emotional exhaustion and depersonalisation, while peer relations predicted personal accomplishment among nurses caring for PLWH.

It is important that nurses have an understanding about burnout and depression, and the consequences they (i.e., burnout and depression) can cause in nurses' professional and personal life. Understanding what burnout and depression are, why they happen, and their signs could help nurses deal with the situation before it spirals out of control.

The above discussions showed the need for in-service training and workshops related to HIV/AIDS knowledge due to the reported lack of HIV/AIDS related knowledge. There is insufficient protective practice environment because the majority of nurses did not know about the availability of Post-Exposure Prophylaxis, which is regarded as a priority to nurses caring for PLWH, and assists in providing nurses with a sense of security. This may be one of the influencing factors toward the nurses' anxiety, which contributes to the nurses' burnout. Burnout was significant among two-thirds of the nurses who participated in the study, hence one-third showed resilience towards caring for PLWH. Knowledge had no significant impact on the level of the psychosocial well-being of nurses caring for PLWH. However, professional nurses reported more burnout than resilience.

\section{Limitations of the study}

The study was conducted at one regional hospital in the Vhembe district of the Limpopo Province where PLWH are cared for. Findings of this study cannot be generalised to all hospitals within the province since contexts are different. This sample is not representative of the different settings as stratified convenience sampling was used.

\section{Recommendations}

\subsection{Nursing education and professional opportunities}

It is important for managers to have a policy in place for educational programmes and induction courses that are supposed to be attended by nurses, and such programmes should be made compulsory or nurses should receive credits on the skills and job-content knowledge acquired (Ramathuba \& Davhana-Maselesele, 2011) and implementation, as well as follow-ups should be done. Nursing education can be restructured to accommodate workplace nurses, newly employed nurses and student nurses. This can be attained by implementing the following:

- Continuous Professional Development (CPD) so as to disseminate and share the latest developments of HIV/ AIDS intervention strategies;

- Orientation of newly employed staff; and

- Nursing education institutions should integrate HIV/AIDS management into their curriculum.

\subsection{Address the health and social impact of caring for PLWH}

\subsubsection{Organizational support}

Workers need to be strengthened and empowered to mobilize their workforce on HIV/AIDS issues through information, education and communication, training and support.

Employee wellness programmes (EWP) - Employee wellness programmes can be designed to assist employees in dealing with the primary and secondary causes of stress and should be inclusive of counselling and psychological services for employees. EWP can be linked with the following measures:

- Internal personal coping strategies should be encouraged

- Provision of positive practice environment may reduce the stress related burnout of nurses, hence, promote a good working environment. 
- The employer should find a viable way to support nurses by providing an environment where nurses can feel comfortable voicing their concerns and anxieties (Elford, 1991; Taerk, Gallop, Lancee, Coates, \& Fanning, 1993), and should acknowledge and understand the legitimacy of nurses' concerns (Elford, 1991).

- Stress Management Training (SMT) and stress management policy or guideline can be employed by hospitals as a way to get employees to maintain stress levels below that which might lead to higher instances of burnout.

Depression and Burnout Interventions: Further research may be conducted that links certain interventions such as narrative writing or topic-specific training to reductions in physiological and psychological stress.

\subsection{Social support}

Social support has been seen as one of the largest predictors of reductions in burnout and stress for nurses; hence it should be taken into consideration in dealing with the psychosocial wellbeing of nurses. Hence, the provision of these support mechanisms has the potential to create a positive practice environment for nurses in South Africa in general and the Vhembe District of the Limpopo Province in particular.

\subsection{Recommendations for future research}

- It is recommended that the following areas for further research be taken into consideration:

- Identification of possible personal variables such as personality traits, ways of coping, and available social support;

- Exploration of current and past stressful life events that could contribute to depression;

- Investigating factors contributing to the inadequate implementation of support programmes for nurses caring for PLWH;

- Determining effects of in-service training, seminars, conferences and workshops among nurses caring for PLWH;

- Exploring nursing role as a caregiver to PLWH beyond just nursing care;

- Establishment of nurses' wellness (physical, psychological and social) monitoring tool.

\section{Conclusion}

The importance of this study was formulating a working description of the level of HIV/AIDS related knowledge, burnout, depression and the impact of AIDS among nurses caring for PLWH, over and above establishing the relationship between HIV/AIDS knowledge and psychosocial wellbeing of nurses caring for PLWH. The study revealed the moderate to high level of HIV related knowledge among nurses caring for PLWH. A moderate level of reported burnout was evident among nurses. In addition, it was revealed that measures of burnout among nurses varied with professional characteristics. AIDS has more impact on assistant nurses than other nursing categories. Assistant nurses reported more severe to extreme depression than other nursing categories. These findings point to differences in social support and HIV and AIDS knowledge needs across professional characteristics.

The study clearly highlighted no relationship between HIV and AIDS related knowledge and psychosocial wellbeing of nurses caring for PLWHA. Hence a strong association was evident between the measures of AIDS impact, as well as measures of burnout. There was no relationship between depression and measures on burnout and AIDS impact. All in all, the findings suggests that nursing education with regard to HIV/AIDS still need an improved approach, for nurses to be well capacitated and supported in their care giving role.

\section{Funding acknowledgement}

This research was supported by the Atlantic Philanthropies project awarded to the North-West University, Mafikeng campus.

\section{Author contribution}

MD-M is the project supervisor who supervised the whole study. L.M. conducted the study, data collection and analysis. L.M. and M.D-M wrote the manuscript.

\section{Competing interests}

The authors declare that they have no financial and personal relationship(s) which may have inappropriately influenced them in writing this article.

\section{Acknowledgements}

The authors acknowledge the contribution of Dr. D. Ramathuba in the recruitment of participants and facilitation of data collection; Mr. D. Chueu, for his constant motivation and encouragement; Prof. O. N. Makhubele-Nkondo, for her expertise; and all nurses who participated in the study.

\section{R E F E R E N C E S}

Andersen, I., Thielen, K., Nygaard, E., \& Diderichsen, F. (2009). Social inequality in the prevalence of depressive disorders. Journal of Epidemiological Community Health, 63, 575-581. http:// dx.doi.org/10.1177/1403494811424611.

Askarian, M., Hashemi, Z., Jaafari, P., \& Assadian, O. (2006). Knowledge about HIV infection and attitude of nursing staff towards patients with AIDS in Iran. Infection Control and Hospital Epidemiology, 1, 48-53. PMID: 16418987.

Beck, A. T. (1967). Depression: Clinical, experimental, and theoretical aspects. New York: Hoeber. (Republished 1972) as Depression: Causes and treatment. Philadelphia: University of Pennsylvania Press.

Bellani, M. L., Furlani, F., Gnecchi, M., Pezzotta, P., Trotti, E. M., \& Bellotti, G. G. (1996). Burnout and related factors among HIV/ AIDS health care workers. AIDS Care, 8(2), 207-221. 
Bennett, L. (1991). The experience of nurses working with hospitalized AIDS patients. Australian Journal of Social Issues, 27, 125-143.

Bennett, L., \& Kelaher, M. (1993). Variables contributing to experiences of grief in HIV/AIDS health care professionals. Journal of Community Psychology, 21(3), 210-217.

Bennett, L., Miller, D., \& Ross, M. (1995). Health workers and AIDS: Research, intervention and current issues in burnout and response. CRC Press. ISBN-10: 3718656604.

Bradley-Springer, L., Stevens, L., \& Webb, A. (2010). Every nurse is an HIV nurse. American Journal of Nursing, 110(3), 32-39.

Brown, G. (2004). An HIV/AIDS issue in nursing practice. Minority Nurse Newsletter, 11, 2.

Central Intelligence Agency. (2011). "CIA world fact book 2011" people living with the HIV virus.

Chandra, P. S., Jairam, K. R., \& Jacob, A. (2004). Factors related to staff stress in HIV/AIDS related palliative care. Indian Journal of Palliate Care, 10(2), 48-54.

Davhana-Maselesele, M., \& Igumbor, J. O. (2008). Mental health impact of caring for persons living with HIV and AIDS among nurses in the Limpopo Province. Curationis, 31(2), 67-73.

Deeks, S. G., Lewin, S. R., \& Havlir, D. V. (2013). The end of AIDS: HI infection as a chronic disease. The Lancet, 382, 1525-1533. http://dx.doi.org/10.1016/S0140-6736(13)61809-7.

Delobelle, P., Rawlinson, J. J. L., Ntuli, S., Malatsi, I., Decock, R., \& Depoorter, A. M. (2009). HIV/AIDS knowledge, attitudes, practices and perceptions of rural nurses in South Africa. Journal of Advanced Nursing, 65(5), 1061-1073. http://dx.doi.org/ 10.1111/j.1365-2648.2009.04973.x.

DOH Limpopo. (2008). Final Limpopo DHSD 2008/09-11 health-annual performance plan-vote 7 .

Effa-Heap, G. (1997). The attitude of Nigerian nurses to HIV/AIDS patients at university college hospital. Ibadan, societies' d'Afrique et Sida, 17-18, 2-4.

Elford, J. (1991). Health care workers. AIDS Care, 3, 399-404.

Forrest, S., \& Kanabus, A. (2003). HIV/AIDS Questionnaires. Retrieved from http:/www.alterheros.com/experts/en/2003/ 11/english-hivaids-questionnaires/.

Ghetti, C., Chang, J., \& Gosman, G. (2009). The burnout, psychological skills, and empathy: balint training in obstetrics and gynaecology residents. Journal of Graduate Medical Education, 1(2), 231-235. http://dx.doi.org/10.4300/JGME-D-09-00049.1.

Gueiritault-Chalvin, V., Kalichman, S. C., Demi, A., \& Peterson, J. L. (2000). Work-related stress and occupational burnout in AIDS caregivers: test of a coping model with nurses providing AIDS care. AIDS Care, 12(2), 149-161.

Hable, D., Dussault, G. \& Dovlo, D. nd. Challenges confronting the health workforce in Sub-Saharan Africa. World Hospitals and Health Services, 40(2), 93-100.

Hall, E. J. (nd). The challenges HIV/AIDS pose to nurses in their work environment. www.hsrc.ac.za/Research_Publication18553.phtml. Retrieved online 2010/04/13.

Hall, B. (2005). The art of becoming a nurse healer. Orlando, Florida: Bandido Books.

Hayter, M. (1998). Burnout and AIDS care related factors in community clinical nurse specialist in North England. Journal of Advanced Nursing, 29(4), 984-993.

HIV and AIDS in South Africa.(2010). Retrieved from http://www. avert.org/aidssouthafrica.htm.

HIV and AIDS in South Africa.(2011). http://www.avert.org/ aidssouthafrica.htm Accessed 15 June 2012.

Iacovides, A., Fountoulakis, K. N., Kaprinis, S. T., \& Kaprinis, G. (2003). The relationship between job stress, burnout and clinical depression. Journal of Affective Disorders, 75(2003), 209-221.

Jodas, D. A., \& Haddad, M. C. L. (2009). Burnout syndrome among nursing staff from an emergency department of a university hospital. Acta Paulista de Enfermagem, 22(2), 192-197. Retrieved from http://dx.doi.org/10.1590/S0103-21002009000200012.

Lohrman, C., Vilimaki, M., Suominen, T., Muinonen, U., Dassen, T., \& Peate, I. (2000). German nursing students' knowledge of and attitudes towards HIV and AIDS: two decades after AIDS cases. Journal of Advanced Nursing, 31, 696-703.

Maslach, C., \& Jackson, S. E. (1981). The measurement of experienced burnout. Journal of Occupational Behaviour, 2, 99-113.

Maslach, C., Jackson, S., \& Leiter, M. (1996). Maslach burnout inventory manual (3rd ed.). Palo Alto, CA: Consulting Psychologists Press.

Mavhandu-Mudzusi, A. H., Netshandama, V. O., \& DavhanaMaselesele, M. (2007). Nurses' experiences of delivering voluntary counselling and testing services for people with HIV/AIDS in the Vhembe District, Limpopo Province, South Africa. Nursing Health Sciences, 9(4), 254-262.

Oyeyemi, A., Oyeyemi, B., \& Bello, I. (2006). Caring for patients living with AIDS: knowledge, attitude and global level of comfort. Journal of Advanced Nursing, 53, 196-204.

Polgar, M. (2003). Beck Depression Inventory. Yahoo health article. Gale content. Retrieved from http://health.yahoo.net/galecontent/ beck-depression-inventory.

Ramathuba, D. U., \& Davhana-Maselesele, M. (2011). Experiences of nurses caring for people living with HIV and AIDS in Vhembe district, Limpopo Province. Life Science Journal, 8(S1), 30-37.

Ramathuba, D. U., \& Davhana-Maselesele, M. (2013). Challenges HIV/AIDS poses on the nursing workforce in rural health setting in Vhembe district, Limpopo Province, South Africa. African Journal for Physical, Health Education, Recreation and Dance, 19(S1), 23-34.

Schaeffer, R. L., Mendenhall, W., \& Ott, L. (2006). Elementary survey sampling (6th ed.). Thompson Brooks/Cole.

Shisana, O., Hall, E. J., Maluleke, K. R., Stoker, D. J., Schwabe, C., Colvin, M., et al. (2004). HIV/AIDS prevalence among South African Health workers. South African Medical Journal, 94(10), 846-850.

South African Institute of Race Relations. (2013). 86\% doctor vacancy rate in Limpopo. Press release. Retrieved from http:// www.moneyweb.co.za/archive/86-doctor-vacancy-rate-inlimpopo-sairr/.

South African national AIDS council. (2013). Limpopo provincial AIDS spending assessment summary brief (2007/ 08-2009/10).

Statistics South Africa. (2009). Living conditions survey 2008/2009: Poverty profile of South Africa. Application of the poverty lines on the LCS 2008/2009.

Statistics South Africa. (2011). Midyear population estimates 2010. Statistical release (p. P0302).

Statistics South Africa. (2013). Midyear population estimates 2013. Statistical release (p. P0302).

Suominen, T., Koponen, N., Mockiene, V., Raid, U., Istomina, N., Vänskä, M.-L., et al. (2010). Nurses' knowledge and attitudes to HIV/AIDS- an international comparison between Finland, Estonia and Lithuania. International Journal of Nursing Practice, 16, 138-147. http://dx.doi.org/10.1111/j.1440-172X.2010.01822.x.

Taerk, G., Gallop, R. M., Lancee, W. J., Coates, R. A., \& Fanning, M. (1993). Recurrent themes of concern in groups for health care professionals. AIDS Care, 5, 215-222.

The Psychosocial Working Group. (2003). Psychosocial intervention in complex emergencies: A conceptual framework. Center for international health studies.

Theorell, T., Nyberg, A., Leineweber, C., Magnusson Hanson, L. L., Oxenstierna, G., \& Westerlun, H. (2012). Non-listening and self-centred leadership - relationships to socioeconomic conditions and employee mental health. PLoS ONE, 7(9), e44119. http://dx.doi.org/10.1371/journal.pone.0044119. 
UNAIDS. (2008). Progress report on declaration of commitment on HIV and AIDS. Republic of South Africa. Geneva: UNAIDS.

UNAIDS. (2012). Global AIDS report for South Africa 2012. Republic of South Africa, Geneva: UNAIDS.

Uys, L. R. (2003). Combating HIV/AIDS stigma: a workshop manual for nurses. San Francisco: SANNAM, University of California.

Visintini, R., Campanini, E., Fossati, A., Bagnato, M., Novella, L., \& Maffei, C. (1996). Psychological stress in nurses' relationship with HIV-infected patient: the risk of burnout syndrome. AIDS Care, 8(2), 183-194.

Walusimbi, M., \& Okonsky, J. G. (2004). Knowledge and attitude of nurses caring for patients with HIV/AIDS in Uganda. Applied Nursing Research, 17(2), 92-99.

WHO, UNICEF, \& UNAIDS. (2010). Towards universal access: Scaling up priority HIV/AIDS interventions in the health sector. Progress Report. World Health Organization, 2010. 